Received: 26 April 2017

Accepted: 22 August 2017

Published online: 07 September 2017

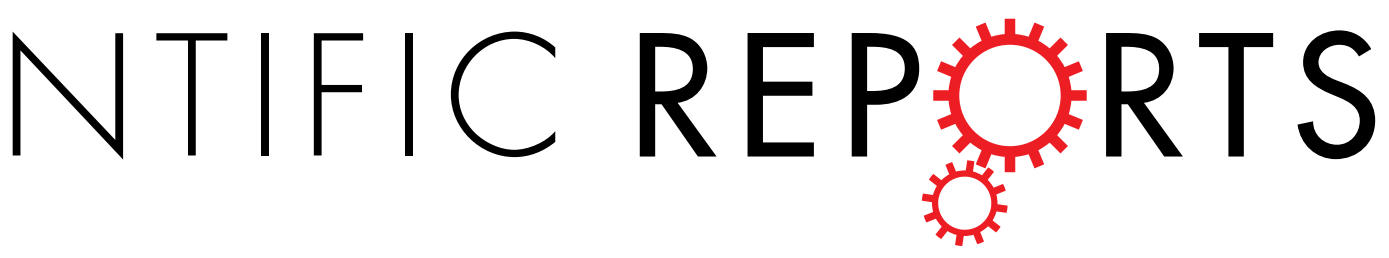

\title{
Low body surface area predicts hepatotoxicity of nintedanib in patients with idiopathic pulmonary fibrosis
}

Satoshi Ikeda $\mathbb{1}^{1,2}{ }^{2}$, Akimasa Sekine ${ }^{1}$, Tomohisa Baba ${ }^{1}$, Yumie Yamanaka ${ }^{1}$, Shinko Sadoyama ${ }^{1}$, Hideaki Yamakawa ${ }^{1}$, Tsuneyuki Odaa ${ }^{1}$, Ryo Okuda $^{1}$, Hideya Kitamura ${ }^{1}$, Koji Okudela ${ }^{2}$, Tae Iwasawa ${ }^{3}$, Kenichi Ohashi ${ }^{2}$, Tamiko Takemura ${ }^{4}$ \& Takashi Ogura ${ }^{1}$

After the commercialization of nintedanib in Japan, a high incidence of hepatotoxicity resulting in treatment interruption was noted in idiopathic pulmonary fibrosis (IPF) patients treated with nintedanib in our hospital. This study aimed to clarify the risk factors for hepatotoxicity of nintedanib. Sixty-eight consecutive cases of IPF newly treated with nintedanib at a dose of $150 \mathrm{mg}$ twice daily from September 2015 to September 2016 were enrolled: 46 patients (67.6\%) exhibited aspartate aminotransferase (AST) and/or alanine aminotransferase (ALT) elevation and 16 patients (23.5\%) also had a Common Terminology Criteria for Adverse Events (CTCAE) grade $\geq 2$. Body surface area (BSA) was significantly lower in the CTCAE grade $\geq 2$ group than in another group. A multivariate logistic regression analysis showed that the association between BSA and AST/ALT elevation with CTCAE grade $\geq 2$ was statistically significant. Eight of 10 patients who resumed nintedanib at a reduced dose of $100 \mathrm{mg}$ twice daily after interruption due to hepatotoxicity did not again develop AST/ALT elevation. In conclusion, a low BSA was associated with hepatotoxicity of nintedanib at a dose of $150 \mathrm{mg}$ twice daily. It would be a good option for patients with a small physique to start nintedanib at a dose of $100 \mathrm{mg}$ twice daily and then increase if possible after confirming its safety.

Nintedanib is a small-molecule tyrosine kinase inhibitor that inhibits vascular endothelial growth factor, platelet-derived growth factor, and fibroblast growth factor ${ }^{1,2}$. Two randomized phase III trials (INPULSIS ${ }^{\mathrm{TM}}-1$ and -2) showed that nintedanib reduced the decline in forced vital capacity (FVC) in patients with idiopathic pulmonary fibrosis (IPF) with a manageable side effect profile ${ }^{3-5}$. Based on these trial results, nintedanib was approved for IPF by the Pharmaceutical and Medical Devices Agency in Japan and was clinically deployed from September 2015.

However, after the commercialization of nintedanib for IPF, a high incidence of hepatotoxicity resulting in treatment interruption was noted in our hospital. We previously reported that 11 of 32 patients with IPF newly treated with nintedanib at a dose of $150 \mathrm{mg}$ twice daily from September to December 2015 exhibited aspartate aminotransferase (AST) and/or alanine aminotransferase (ALT) elevation with the Common Terminology Criteria for Adverse Events (CTCAE) grade $\geq 2^{6,7}$. In addition, this study showed that body mass index (BMI) and body surface area (BSA) were significantly lower in patients who presented with hepatotoxicity, and that hepatotoxicity was more frequent when BSA was $<1.50 \mathrm{~m}^{2}$ and BMI was $<22$.

In the present study, we accumulated more cases and conducted further investigations to clarify the risk factors for hepatotoxicity of nintedanib in patients with IPF.

\footnotetext{
${ }^{1}$ Kanagawa Cardiovascular and Respiratory Center, Department of Respiratory Medicine, Yokohama, 236-0051, Japan. ${ }^{2}$ Yokohama-city University Graduate School of Medicine, Department of Pathology, Yokohama, 236-0004, Japan. ${ }^{3}$ Kanagawa Cardiovascular and Respiratory Center, Department of Radiology, Yokohama, 236-0051, Japan.

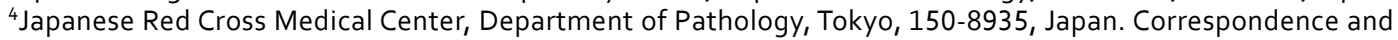
requests for materials should be addressed to S.I. (email: isatoshi0112@gmail.com) orT.O. (email: takaoguogu@ gmail.com)
} 


\begin{tabular}{|c|c|c|c|}
\hline & \multirow[b]{2}{*}{ Our patients } & \multicolumn{2}{|c|}{$\begin{array}{l}\text { Nintedanib group in } \\
\text { INPULSIS trials }\end{array}$} \\
\hline & & \begin{tabular}{|l|} 
Japanese \\
\end{tabular} & Overall \\
\hline Number of patients & 68 & 76 & 638 \\
\hline Age & $72.0(68.0-76.0)$ & $68.4 \pm 7.6^{*}$ & $66.6 \pm 8.1^{*}$ \\
\hline Gender (male/female) & $52 / 16$ & $62 / 14$ & $507 / 131$ \\
\hline \multicolumn{4}{|l|}{ Physique } \\
\hline Height $(\mathrm{cm})$ & $164(158-169)$ & - & - \\
\hline Body weight (kg) & $57.7(51.2-69.8)$ & $63.8 \pm 11.6^{*}$ & $79.2 \pm 16.6^{*}$ \\
\hline Body mass index & $22.1(19.6-25.0)$ & $24.4 \pm 3.4^{*}$ & $28.1 \pm 4.6^{*}$ \\
\hline Body surface area (DuBois, $\mathrm{m}^{2}$ ) & $1.64(1.48-1.79)$ & - & - \\
\hline \multicolumn{4}{|l|}{ Laboratory data } \\
\hline Aspartate aminotransferase (IU/L) & $21.0(17.8-24.5)$ & - & - \\
\hline Alanine aminotransferase (IU/L) & $14.0(11.0-22.0)$ & - & - \\
\hline Alkaline phosphatase (IU/L) & $241(194-283)$ & - & - \\
\hline Total bilirubin (mg/dL) & $0.50(0.40-0.62)$ & - & - \\
\hline$\gamma$-glutamyl transpeptidase (IU/L) & $28.0(20.0-52.8)$ & - & - \\
\hline Creatinine $(\mathrm{mg} / \mathrm{dL})$ & $0.82(0.69-0.92)$ & - & - \\
\hline Krebs von den Lungen-6 (U/mL) & $1067(694-1560)$ & - & - \\
\hline Surfactant protein D (ng/dL) & $294(182-409)$ & - & - \\
\hline \multicolumn{4}{|l|}{ Pulmonary function test } \\
\hline forced vital capacity (L) & $1.90(1.41-2.35)$ & $2.42 \pm 0.67 *$ & $2.71 \pm 0.76^{*}$ \\
\hline$\%$ forced vital capacity (\%) & $62.3(50.1-72.1)$ & $80.9 \pm 16.6^{*}$ & $79.7 \pm 17.6^{*}$ \\
\hline$\% \operatorname{DLCO}(\%)$ & $50.8(41.3-63.6)$ & $44.6 \pm 11.4^{*}$ & $47.4 \pm 13.5^{*}$ \\
\hline \multicolumn{4}{|l|}{ Six minute walk test } \\
\hline lowest $\mathrm{SpO}_{2}(\%)$ & $82.0(76.0-87.0)$ & - & - \\
\hline walking distance (meter) & $410(340-480)$ & - & - \\
\hline \multicolumn{4}{|l|}{ Concomitant therapy } \\
\hline Prednisolone (\%) & $11(16.2 \%)$ & $9(11.8 \%)$ & $136(21.3 \%)$ \\
\hline Cyclosporine (\%) & $2(2.9 \%)$ & 0 & 0 \\
\hline Cyclophosphamide (\%) & $2(2.9 \%)$ & 0 & 0 \\
\hline Tacrolimus (\%) & $5(7.4 \%)$ & 0 & 0 \\
\hline Pirfenidone (\%) & $2(2.9 \%)$ & 0 & 0 \\
\hline
\end{tabular}

Table 1. Patient characteristics. Categorical data are presented as numbers (percentages) and continuous data are presented as medians (interquartile ranges). *Continuous data in INPULSIS trials are presented as the mean \pm standard deviation. Abbreviations: $\mathrm{DLCO}=$ diffusing capacity for lung carbon monoxide.

\section{Results}

Characteristics. Patient characteristics are summarized in Table 1. Sixty-eight patients with IPF were enrolled in this study of which $76.5 \%$ were male with a median age of 72 years. The median body weight, BMI, and BSA estimated using the Du Bois formula were $57.7 \mathrm{~kg}, 22.1$, and $1.64 \mathrm{~m}^{2}$, respectively. The median \% FVC and $\%$ diffusing capacity for lung carbon monoxide (DLCO) at baseline were $62.3 \%$ and $50.8 \%$, respectively. The most common concomitant drug was prednisolone (16.2\%) followed by tacrolimus (7.4\%). The median follow up period was 235 days (data cut-off date was October 19, 2016).

Hepatotoxicity of nintedanib. Adverse events in terms of hepatotoxicity are summarized in Table 2. A high proportion of patients had elevated levels of liver enzymes: 46 patients (67.6\%) exhibited AST and/or ALT elevation and 16 patients (23.5\%) were CTCAE grade $\geq 2$ with a median interval of 6 days. Three patients experienced acute hypochondriac pain before AST and/or ALT elevation with a CTCAE grade $\geq 2$ were detected. An elevation in $\gamma$-GTP was also frequently observed and CTCAE grade $\geq 2$ appeared in 40 patients (58.8\%).

Comparison of characteristics and examination findings with and without hepatotoxicity. A comparison between a group of 16 patients who demonstrated AST and/or ALT elevation with a CTCAE grade $\geq 2$ and another group of 52 patients is shown in Table 3 . The BSA was significantly lower in the CTCAE grade $\geq 2$ group than in the CTCAE grade $<2$ group $(p=0.0484)$. Body weight was also lower in CTCAE grade $\geq 2$ group, although this difference did not reach statistical significance $(p=0.0765)$. No significant differences were observed in terms of age, gender, laboratory data at the first visit, pulmonary function tests, six minute walk test, and concomitant therapy between the 2 groups.

Risk factors for hepatotoxicity of nintedanib. We evaluated the risk factors for AST and/or ALT elevation with a CTCAE grade $\geq 2$ (Table 4). Referring to the results of comparison with and without hepatotoxicity, 


\begin{tabular}{|c|c|c|c|}
\hline & \multicolumn{3}{|c|}{ CTCAE grading of the worst value } \\
\hline & All grade & $\geq 2$ & $\geq 3$ \\
\hline \multicolumn{4}{|l|}{ Our patients $(\mathrm{N}=68)$} \\
\hline AST elevation & $44(64.7 \%)$ & $14(20.6 \%)$ & $6(8.8 \%)$ \\
\hline ALT elevation & $38(55.9 \%)$ & $12(17.6 \%)$ & $2(2.9 \%)$ \\
\hline AST and/or ALT elevation & $46(67.6 \%)$ & $16(23.5 \%)$ & $6(8.8 \%)$ \\
\hline ALP elevation & $29(42.6 \%)$ & $1(1.5 \%)$ & 0 \\
\hline Total bilirubin elevation & $5(7.4 \%)$ & $3(4.4 \%)$ & $2(2.9 \%)$ \\
\hline$\gamma$-GTP elevation & $40(58.8 \%)$ & $17(25.0 \%)$ & $2(2.9 \%)$ \\
\hline \multicolumn{4}{|c|}{ Nintedanib group in INPULSIS trials } \\
\hline \multicolumn{4}{|c|}{ Japanese patients $(\mathrm{N}=76)$} \\
\hline AST elevation & $26 / 72 *(36.1 \%)$ & $4(5.3 \%)$ & $2(2.6 \%)$ \\
\hline ALT elevation & $30 / 71^{*}(42.3 \%)$ & $4(5.3 \%)$ & $1(1.3 \%)$ \\
\hline AST and/or ALT elevation & - & $5(6.6 \%)$ & $3(3.9 \%)$ \\
\hline \multicolumn{4}{|l|}{ Overall population $(\mathrm{N}=638)$} \\
\hline AST elevation & $134 / 625 *(21.4 \%)$ & $21(3.3 \%)$ & $8(1.3 \%)$ \\
\hline ALT elevation & $169 / 620 *(27.3 \%)$ & $28(4.4 \%)$ & $10(1.6 \%)$ \\
\hline AST and/or ALT elevation & - & $32(5.0 \%)$ & $14(2.2 \%)$ \\
\hline
\end{tabular}

Table 2. Hepatotoxicity. Categorical data are presented as numbers (percentages). *The number of patients whose test results increased $>$ the upper limit of the normal range/the number of patients whose test results were within the reference values at baseline. Abbreviations; AST = aspartate aminotransferase; ALT = alanine aminotransferase; $\mathrm{ALP}=$ alkaline phosphatase; $\mathrm{T}$-Bil $=$ total bilirubin; $\gamma$-GTP $=\gamma$-glutamyl transpeptidase; $\mathrm{CTCAE}=$ Common Terminology Criteria for Adverse Events.

we selected BSA not only as the most possible candidate risk factor, but also as a representative factor related to physique. We also selected age, \%FVC, \%DLCO (these 3 factors had a significant impact on the assessment of severity and/or prognosis of IPF and have little relation with physique), and the baseline AST and ALT levels as candidate risk factors. A multivariate logistic regression analysis showed that the association between BSA and AST and/or ALT elevation with a CTCAE grade $\geq 2$ was statistically significant $(p=0.0457)$.

A ROC curve analysis was used to determine the BSA cut-off values (Fig. 1). The area under the curve for BSA was 0.664 (95\% confidence interval: $0.515-0.813)$ and the cut-off value for which sensitivity + specificity is maximal was $1.58 \mathrm{~m}^{2}(68.8 \%$ sensitivity and $65.4 \%$ specificity).

Treatment after interruption due to hepatotoxicity. Treatments after interruption due to hepatotoxicity are summarized in Table 5. In 16 patients, treatment interruption was required due to AST and/or ALT elevation with a CTCAE grade $\geq 2$. In all cases, hepatic enzyme elevations were completely reversible with treatment interruption. Among 16 patients who needed a treatment interruption due to AST and/or ALT elevation with a CTCAE grade $\geq 2$, re-administration at a reduced dose of $100 \mathrm{mg}$ twice daily was performed in 10 patients. Treatment was successfully continued in 6 patients, whereas it was stopped in 4 patients due to the recurrence of AST and/or ALT elevation with a CTCAE grade $\geq 2$ ( 2 patients) and nausea or fever (1 patient each). On the other hands, the remaining 6 patients who needed a treatment interruption due to AST and/or ALT elevation with a CTCAE grade $\geq 2$ discontinued nintedanib treatment without resumption because of patient rejection or acute hypochondriac pain ( 2 patients each) and a deterioration in their physical condition or eosinophilia ( 1 patient each).

\section{Discussion}

The present study demonstrated the 3 following important clinical observations. First, a low BSA was associated with AST and/or ALT elevation with a CTCAE grade $\geq 2$ when treated with nintedanib at a dose of $150 \mathrm{mg}$ twice daily. Second, $80 \%$ of the patients who resumed nintedanib at a reduced dose of $100 \mathrm{mg}$ twice daily after treatment interruption due to hepatotoxicity did not again develop AST and/or ALT elevation with a CTCAE grade $\geq 2$. Third, $37.5 \%$ of the patients who needed treatment interruption due to hepatotoxicity could not resume nintedanib treatment.

To date, risk factors for hepatotoxicity of nintedanib in patients with IPF have not been fully investigated. However, the present study suggested that a low BSA predicts an AST and/or ALT elevation with a CTCAE grade $\geq 2$ when treating with nintedanib at a dose of $150 \mathrm{mg}$ twice daily. The incidence of hepatotoxicity in the present study was considerably higher than that reported in the INPULSIS trials (as shown in Table 2), whereas factors related to physique such as body weight, BMI, and absolute FVC values were considerably lower than those reported in the INPULSIS trials (Table 1$)^{4}$. Similarly, a sub-analysis of the INPULSIS trials revealed that the incidence of AST and/or ALT elevation was higher in Japanese populations than in overall populations (Table 2), whereas body weight, BMI, and absolute FVC values were lower in Japanese patients than those in the overall

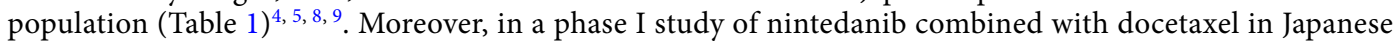
patients with advanced non-small-cell lung cancer, the incidence of hepatotoxicity was higher in patients with a BSA $<1.50 \mathrm{~m}^{2}$ than in patients with a BSA $\geq 1.50 \mathrm{~m}^{210}$. These results indicate that physique is related to hepatotoxicity of nintedanib. Among the factors related to physique, BSA would be the most useful predictive factor. 


\begin{tabular}{|c|c|c|c|}
\hline & hepatotoxicity & no hepatotoxicity & $p$-value \\
\hline Number of patients & 16 & 52 & \\
\hline Age & $75.0(68.8-76.3)$ & $72.0(68.0-76.0)$ & 0.519 \\
\hline Gender (male/female) & $11 / 5$ & $41 / 11$ & 0.502 \\
\hline \multicolumn{4}{|l|}{ Physique } \\
\hline Height $(\mathrm{cm})$ & $160(153-166)$ & $164(158-169)$ & 0.188 \\
\hline Body weight (kg) & $53.2(49.2-57.9)$ & $62.0(52.3-70.3)$ & 0.0765 \\
\hline Body mass index & $21.5(19.4-24.3)$ & $22.4(20.0-25.0)$ & 0.311 \\
\hline Body surface area $\left(\right.$ DuBois, $\left.\mathrm{m}^{2}\right)$ & $1.52(1.45-1.67)$ & $1.67(1.54-1.80)$ & 0.0484 \\
\hline \multicolumn{4}{|l|}{ Laboratory data } \\
\hline Aspartate aminotransferase (IU/L) & $20.5(16.5-31.5)$ & $21.0(18.0-24.0)$ & 0.612 \\
\hline Alanine aminotransferase (IU/L) & $14.0(11.0-29.0)$ & $14.0(11.0-20.3)$ & 0.524 \\
\hline Alkaline phosphatase (IU/L) & $247(211-280)$ & $240(189-283)$ & 0.608 \\
\hline Total bilirubin $(\mathrm{mg} / \mathrm{dL})$ & $0.50(0.40-0.62)$ & $0.50(0.40-0.62)$ & 1.00 \\
\hline$\gamma$-glutamyl transpeptidase (IU/L) & $28.5(21.5-63.8)$ & $28.0(20.0-48.0)$ & 0.573 \\
\hline Creatinine $(\mathrm{mg} / \mathrm{dL})$ & $0.80(0.68-0.90)$ & $0.83(0.70-0.92)$ & 0.385 \\
\hline Krebs von den Lungen- $6(\mathrm{U} / \mathrm{mL})$ & $920(694-1356)$ & $1080(766-1592)$ & 0.800 \\
\hline Surfactant protein D (ng/dL) & $262(167-440)$ & $309(188-400)$ & 0.691 \\
\hline \multicolumn{4}{|l|}{ Pulmonary function test } \\
\hline forced vital capacity (L) & $1.75(1.37-2.42)$ & $1.96(1.65-2.34)$ & 0.457 \\
\hline \%forced vital capacity (\%) & $64.0(55.0-71.7)$ & $60.9(48.9-72.7)$ & 0.822 \\
\hline$\% \operatorname{DLCO}(\%)$ & $51.4(36.1-60.1)$ & $50.4(42.2-65.6)$ & 0.464 \\
\hline \multicolumn{4}{|l|}{ Six-minute walk test } \\
\hline lowest $\mathrm{SpO}_{2}(\%)$ & $81.5(77.5-87.0)$ & $82.0(76.0-87.0)$ & 0.922 \\
\hline walking distance (meter) & $378(281-450)$ & $430(355-480)$ & 0.299 \\
\hline \multicolumn{4}{|l|}{ Concomitant therapy } \\
\hline Prednisolone (\%) & $3(18.8 \%)$ & $8(15.4 \%)$ & 0.712 \\
\hline Cyclosporine (\%) & 0 & $2(3.8 \%)$ & 1.00 \\
\hline Cyclophosphamide (\%) & 0 & $2(3.8 \%)$ & 1.00 \\
\hline Tacrolimus (\%) & $1(6.2 \%)$ & $4(7.7 \%)$ & 1.00 \\
\hline Pirfenidone (\%) & $1(6.2 \%)$ & $1(1.9 \%)$ & 0.418 \\
\hline
\end{tabular}

Table 3. Comparison of characteristics and examination findings with and without hepatotoxicity. Categorical data are presented as numbers (percentages) while continuous data are presented as medians (interquartile ranges). Fisher's exact test was used to compare categorical data and the Mann-Whitney U test was used to compare continuous data. Abbreviations: $\mathrm{DLCO}=$ diffusing capacity for lung carbon monoxide.

\begin{tabular}{|l|l|l|l|}
\hline & $\begin{array}{l}\text { Odds } \\
\text { ratio }\end{array}$ & $\begin{array}{l}\text { 95\% confidence } \\
\text { interval }\end{array}$ & p-value \\
\hline Body surface area & 0.0208 & $0.000468-0.929$ & 0.0457 \\
\hline Age & 1.01 & $0.888-1.15$ & 0.891 \\
\hline \% forced vital capacity & 0.988 & $0.947-1.03$ & 0.564 \\
\hline $\begin{array}{l}\text { \% diffusing capacity for } \\
\text { lung carbon monoxide }\end{array}$ & 0.999 & $0.961-1.04$ & 0.950 \\
\hline $\begin{array}{l}\text { Baseline aspartate } \\
\text { aminotransferase }\end{array}$ & 1.09 & $0.950-1.25$ & 0.224 \\
\hline $\begin{array}{l}\text { Baseline alanine } \\
\text { aminotransferase }\end{array}$ & 1.00 & $0.932-1.08$ & 0.994 \\
\hline
\end{tabular}

Table 4. Multivariate logistic regression analysis.

It is also noteworthy that 8 of 10 patients (80\%) successfully resumed nintedanib at a reduced dose of $100 \mathrm{mg}$ twice daily after treatment interruption due to AST and/or ALT elevation with a CTCAE grade $\geq 2$ at a dose of $150 \mathrm{mg}$ twice daily. These 8 patients also had a small physique, with a median BSA of $1.57 \mathrm{~m}^{2}$. According to the pharmacokinetic analysis of nintedanib in Japanese patients, the area under the concentration-time curve and maximum concentration in plasma at a steady state were approximately two-times higher at a dose of $150 \mathrm{mg}$ twice daily than those at a dose of $100 \mathrm{mg}$ twice daily $(39.7 \mathrm{ng} / \mathrm{ml}$ vs $20.0 \mathrm{ng} / \mathrm{ml}$ and $218 \mathrm{ng} \cdot \mathrm{h} / \mathrm{ml} \mathrm{vs} 115 \mathrm{ng} \cdot \mathrm{h} /$ $\mathrm{ml}$, respectively $)^{11}$. These data suggested that hepatotoxicity would be associated with the plasma concentration of nintedanib. In the present study, it was speculated that the patients with a small build tended to have a high serum concentration at a dose of $150 \mathrm{mg}$ twice daily, and thus, were more likely to develop AST and/or ALT elevation. However, as the bioavailability of nintedanib is relatively low, serum concentration of nintedanib may 


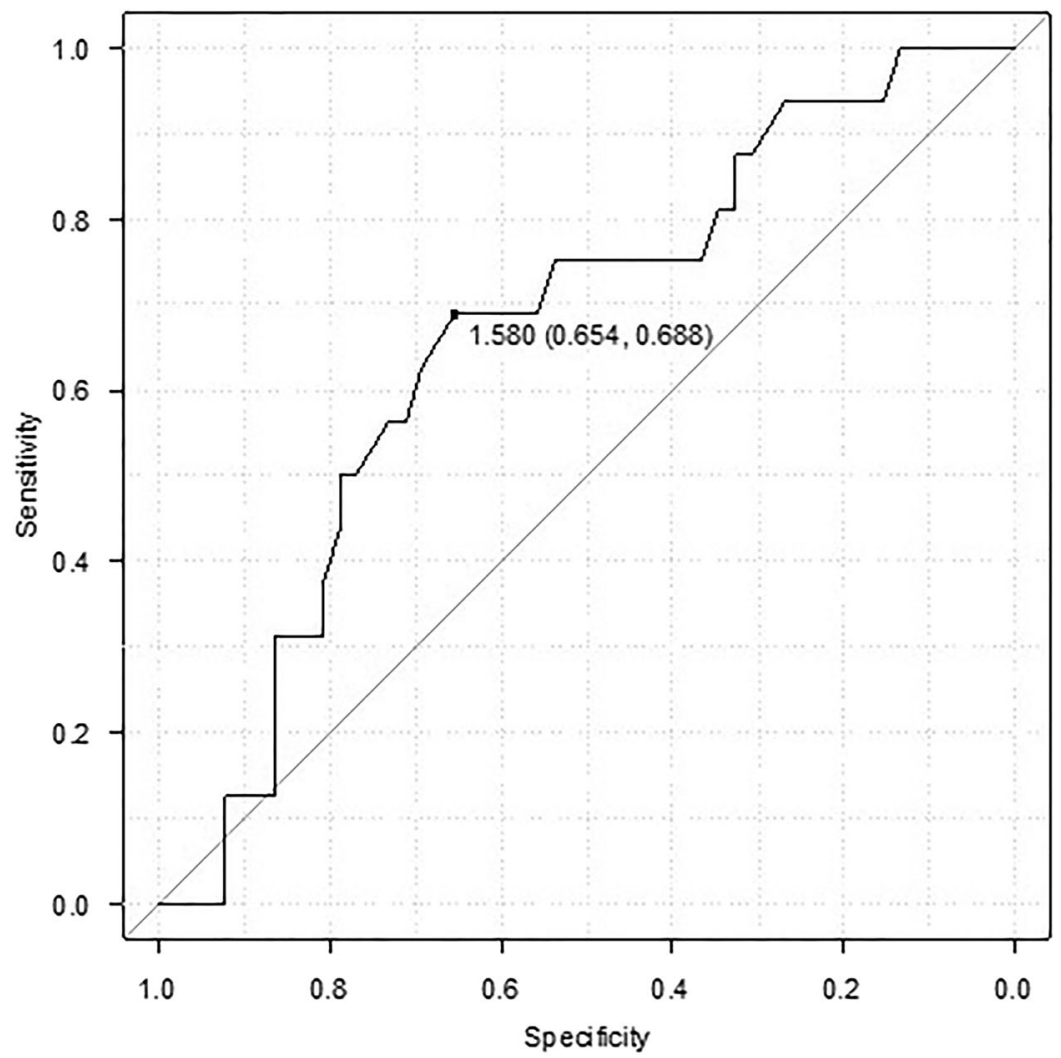

Figure 1. Receiver operating characteristic curve analysis. A receiver operating characteristic curve analysis was used to determine the cut-off values of body surface area. The area under the curve was 0.664 (95\% confidence interval: $0.515-0.813$ ) and the cut-off value for which sensitivity + specificity is maximal was $1.58 \mathrm{~m}^{2}$ (68.8\% sensitivity and $65.4 \%$ specificity).

\begin{tabular}{|l|l|}
\hline & $\mathbf{n}$ \\
\hline Resume at a reduced dose of 100 mg twice daily & 10 \\
\hline Continue & 6 \\
\hline Re-interrupt & 4 \\
\hline recurrence of AST/ALT elevation with CTCAE grade $\geq 2$ & 2 \\
\hline nausea & 1 \\
\hline fever & 1 \\
\hline Discontinue without resumption & 6 \\
\hline patient rejection & 2 \\
\hline acute hypochondriac pain & 2 \\
\hline deterioration of physical condition & 1 \\
\hline eosinophilia in peripheral blood & 1 \\
\hline
\end{tabular}

Table 5. Treatment after interruption due to AST and/or ALT elevation with a CTCAE grade $\geq 2$. Abbreviations; $\mathrm{AST}=$ aspartate aminotransferase; $\mathrm{ALT}=$ alanine aminotransferase; $\mathrm{CTCAE}=\mathrm{Common}$ Terminology Criteria for Adverse Events.

differ among individuals. Therefore, further pharmacokinetic analysis in various patients with different physiques is required.

In the present study, an AST and/or ALT elevation was completely reversible with a treatment interruption. However, 6 of the 16 patients (37.5\%) who needed a treatment interruption due to AST and/or ALT elevation with a CTCAE grade $\geq 2$ could not resume nintedanib treatment. It might have been unavoidable that those patients could not resume because of concerns over noteworthy side-effects such as eosinophilia in the peripheral blood and acute hypochondriac pain. However, at least another 3 patients were highly likely to have continued nintedanib treatment over a longer period if it were not for the interruption. In addition, recently, an interim analysis of the INPULSIS ${ }^{\circledR}$-ON study showed that the beneficial effect of nintedanib on slowing disease progression was maintained and the change from baseline FVC was consistent over 2 or more years ${ }^{12}$. Thus, it is very important to continue nintedanib treatment as long as possible without interruption and/or discontinuation by setting 
the appropriate dosage for individual patients. For patients with a small physique, especially Japanese and eastern Asian patients with a BSA $<1.58 \mathrm{~m}^{2}$, it would be a good option to start nintedanib at a dose of $100 \mathrm{mg}$ twice daily and then increase the dose to $150 \mathrm{mg}$ twice daily if possible after confirming its safety.

A limitation of the present study was the retrospective single-center study design. In addition, frequent blood sampling may provide an opportunity to detect a temporal AST and/or ALT elevation that may recover spontaneously. In the present study, the median interval from nintedanib initiation to AST and/or ALT elevation with a CTCAE grade $\geq 2$ was only 6 days, whereas the protocol of the INPULSIS trials specified that hepatic enzymes must be examined once every 2 weeks during the first 6 weeks. The short observation period was also another limitation when assessing long-term safety.

In conclusion, a low BSA was associated with hepatotoxicity of nintedanib at a dose of $150 \mathrm{mg}$ twice daily in patients with IPF. To continue nintedanib treatment as long as possible without interruption and/or discontinuation, it would be a good option for patients with a small physique to start nintedanib at a dose of $100 \mathrm{mg}$ twice daily and then increase the dose to $150 \mathrm{mg}$ twice daily if possible after confirming its safety.

\section{Methods}

Patients and settings. This retrospective study was performed at the Kanagawa Cardiovascular and Respiratory Center in Yokohama City, Kanagawa, Japan. All consecutive cases of IPF newly treated with nintedanib at a dose of $150 \mathrm{mg}$ twice daily from September 2015 to September 2016 were enrolled. The diagnosis of IPF was based on the official American Thoracic Society/European Respiratory Society/Japanese Respiratory Society/Latin American Thoracic Association statement of $2011^{13}$. Patients with a previous history of nintedanib treatment (formerly known as BIBF1120) were excluded. This study has been carried out in accordance with the Declaration of Helsinki. The Ethics Committee of the Kanagawa Cardiovascular and Respiratory Center approved the study protocol (Approval date: November 30, 2016; Approved number: KCRC-16-0006) and patient consent was waived because this was a retrospective study and anonymity was secured.

Data availability. The datasets generated during and/or analysed during the current study are available from the corresponding author on reasonable request.

Clinical and laboratory findings. Clinical and laboratory data used in this study were retrieved from patient medical records and included age, gender, height, body weight, laboratory data [AST, ALT, alkaline phosphatase (ALP), total bilirubin (T-Bil), $\gamma$-glutamyl transpeptidase $(\gamma$-GTP), serum creatinine, Krebs von den Lungen-6 (KL-6), and surfactant protein D (SP-D)], pulmonary function tests, six minute walk test, and concomitant therapy. In all cases, hepatic enzymes were examined at least once within a week of nintedanib treatment initiation and at least once every $2-4$ weeks thereafter.

Assessment and response for the hepatotoxicity. The worst examination values were graded using the CTCAE ver. 4.0 ${ }^{14}$. An elevation in AST and ALT was defined as follows: grade 1 was $>3.0 \times$ the upper limit of the normal range $(\mathrm{ULN})$, grade 2 was $>3.0-5.0 \times \mathrm{ULN}$, grade 3 was $>5.0-20.0 \times \mathrm{ULN}$, and grade 4 was $>20.0 \times$ ULN. When a patient developed AST and/or ALT elevation with CTCAE grade $\geq 2$, treatment interruption or dose reduction was needed in accordance with the guide for appropriate use of nintedanib $\left(\mathrm{Ofev}^{\circledR}\right)^{15}$.

Statistical analysis. Categorical data are presented as numbers (percentages) while continuous data are presented as medians (interquartile ranges). Fisher's exact test was used to compare categorical data and the Mann-Whitney $U$ test was used to compare continuous data. A multivariate logistic regression analysis was performed to verify the risk of hepatotoxicity. A receiver operating characteristic (ROC) curve analysis was used to determine the optimal cut-off values for the risk factor; values with maximum joint sensitivity and specificity were selected. A $p$-value of $<0.05$ was considered statistically significant. All statistical analyses were performed with EZR (Saitama Medical Center, Jichi Medical University, Saitama, Japan) ${ }^{16}$, which is a graphical user interface for R Version 3.2.2 (The R Foundation for Statistical Computing, Vienna, Austria).

\section{References}

1. Hilberg, F. et al. BIBF 1120: triple angiokinase inhibitor with sustained receptor blockade and good antitumor efficacy. Cancer Res. 68, 4774-4782 (2008)

2. Wollin, L., Maillet, I., Quesniaux, V., Holweg, A. \& Ryffel, B. Anti-fibrotic and anti-inflammatory activity of the tyrosine kinase inhibitor nintedanib in experimental models of lung fibrosis. J Pharmacol Exp Ther. 349, 209-220 (2014).

3. Richeldi, L. et al. Design of the INPULSIS ${ }^{\mathrm{TM}}$ trials: two phase 3 trials of nintedanib in patients with idiopathic pulmonary fibrosis. Respir Med. 108, 1023-30 (2014).

4. Richeldi, L. et al. Efficacy and safety of nintedanib in idiopathic pulmonary fibrosis. N Engl J Med. 370, 2071-2082 (2014).

5. Corte, T. et al. Safety, tolerability and appropriate use of nintedanib in idiopathic pulmonary fibrosis. Respir Res. 16, 116 (2015).

6. Ikeda, S. et al. Hepatotoxicity of nintedanib in patients with idiopathic pulmonary fibrosis: a single-center experience. Respir Investig. 55, 51-54 (2017).

7. Azuma, A. Safety management of treatment with nintedanib in clinical practice of IPF. Respir Investig. 55, 1 (2017).

8. Azuma, A. et al. Nintedanib in Japanese patients with idiopathic pulmonary fibrosis: A subgroup analysis of the INPULSIS ${ }^{\circledR}$ randomized trials. Respirology. 22, 750-757 (2016)

9. Pharmaceuticals and Medical Devices Agency [Internet], Japan: [The examination report of nintedanib-ethanesulfonate] Available from: http://www.pmda.go.jp/PmdaSearch/iyakuDetail/GeneralList/3999039M1 [accessed December 17, 2016].

10. Okamoto, I. et al. Tolerability of nintedanib (BIBF 1120) in combination with docetaxel: a phase 1 study in Japanese patients with previously treated non-small-cell lung cancer. J Thorac Oncol. 10, 346-52 (2015).

11. Ogura, T. et al. Safety and pharmacokinetics of nintedanib and pirfenidone in idiopathic pulmonary fibrosis. Eur Respir J. 45, 1382-92 (2015).

12. Crestani, B. et al. Interim analysis of nintedanib in an open-label extension of of the INPULSIS ${ }^{\circledR}$ trials (INPULSIS $^{\circledR}$-ON). Abstract presented at the ERS International Congress 2015, Amsterdam, September 26-30, 2015. 
13. Raghu, G. et al. An official ATS/ERS/JRS/ALAT statement: idiopathic pulmonary fibrosis: evidence-based guidelines for diagnosis and management. Am J Respir Crit Care Med. 183, 788-824 (2011).

14. Common Terminology Criteria for Adverse Events (CTCAE) ver.4.0. http://ctep.cancer.gov/protocolDevelopment/electronic applications/ctc.htm\#ctc_40 (accessed December 17, 2016).

15. Boehringer Ingelheim [Internet], Japan: [Guide for appropriate use of nintedanib $\left(\mathrm{Ofev}^{\circledR}\right)$ ] Available from: https://www. boehringerplus.jp/sites/all/themes/jp/nbi/pdf/product-page/basic-documents/products/attach/pdf/ofe_cap_guide.pdf [accessed December 17, 2016].

16. Kanda, Y. Investigation of the freely available easy-to-use software 'EZR' for medical statistics. Bone Marrow Transplant. 48, 452-458 (2013).

\section{Acknowledgements}

The authors would like to thank Morihito Takita and Atsuko Yoshizawa (Center for Advancing Translational Sciences, Kanagawa Prefectural Hospital Organization, Japan) for their advice concerning the statistical analysis. The authors would also like to thank Yukiko Ogasawara (Clinical Research Center, Kanagawa Cardiovascular and Respiratory Center, Japan) for extracting patient data.

\section{Author Contributions}

S. Ikeda was involved in data acquisition; S. Ikeda, A. Sekine, T. Baba, Y. Yamanaka, S. Sadoyama, H. Yamakawa, T. Oda, R. Okuda, H. Kitamura, K. Okudela, T. Iwasawa, K. Ohashi, T. Takemura, and T. Ogura were involved in the analysis and interpretation of the clinical data; S. Ikeda, T. Baba, and T. Iwasawa were involved in the analysis and interpretation of radiological findings; K. Okudela, K. Ohashi, and T. Takemura were involved in the analysis and interpretation of the pathological findings; and S. Ikeda, A. Sekine, and T. Ogura were involved in drafting the manuscript. All authors read and approved the final manuscript.

\section{Additional Information}

Competing Interests: S. Ikeda, A. Sekine, T. Baba, Y. Yamanaka, S. Sadoyama, H. Yamakawa, T. Oda, R. Okuda, H. Kitamura, K. Okudela, T. Iwasawa, K. Ohashi, and T. Takemura declare that no potential conflicts of interest exist with any companies/organizations whose products or services may be discussed in this article. T. Ogura received an honorarium from Boehringer Ingelheim Co., Ltd. This research received no specific grant from any funding agency in the public, commercial, or not-for-profit sectors.

Publisher's note: Springer Nature remains neutral with regard to jurisdictional claims in published maps and institutional affiliations.

(c) (i) Open Access This article is licensed under a Creative Commons Attribution 4.0 International

License, which permits use, sharing, adaptation, distribution and reproduction in any medium or format, as long as you give appropriate credit to the original author(s) and the source, provide a link to the Creative Commons license, and indicate if changes were made. The images or other third party material in this article are included in the article's Creative Commons license, unless indicated otherwise in a credit line to the material. If material is not included in the article's Creative Commons license and your intended use is not permitted by statutory regulation or exceeds the permitted use, you will need to obtain permission directly from the copyright holder. To view a copy of this license, visit http://creativecommons.org/licenses/by/4.0/.

(c) The Author(s) 2017 